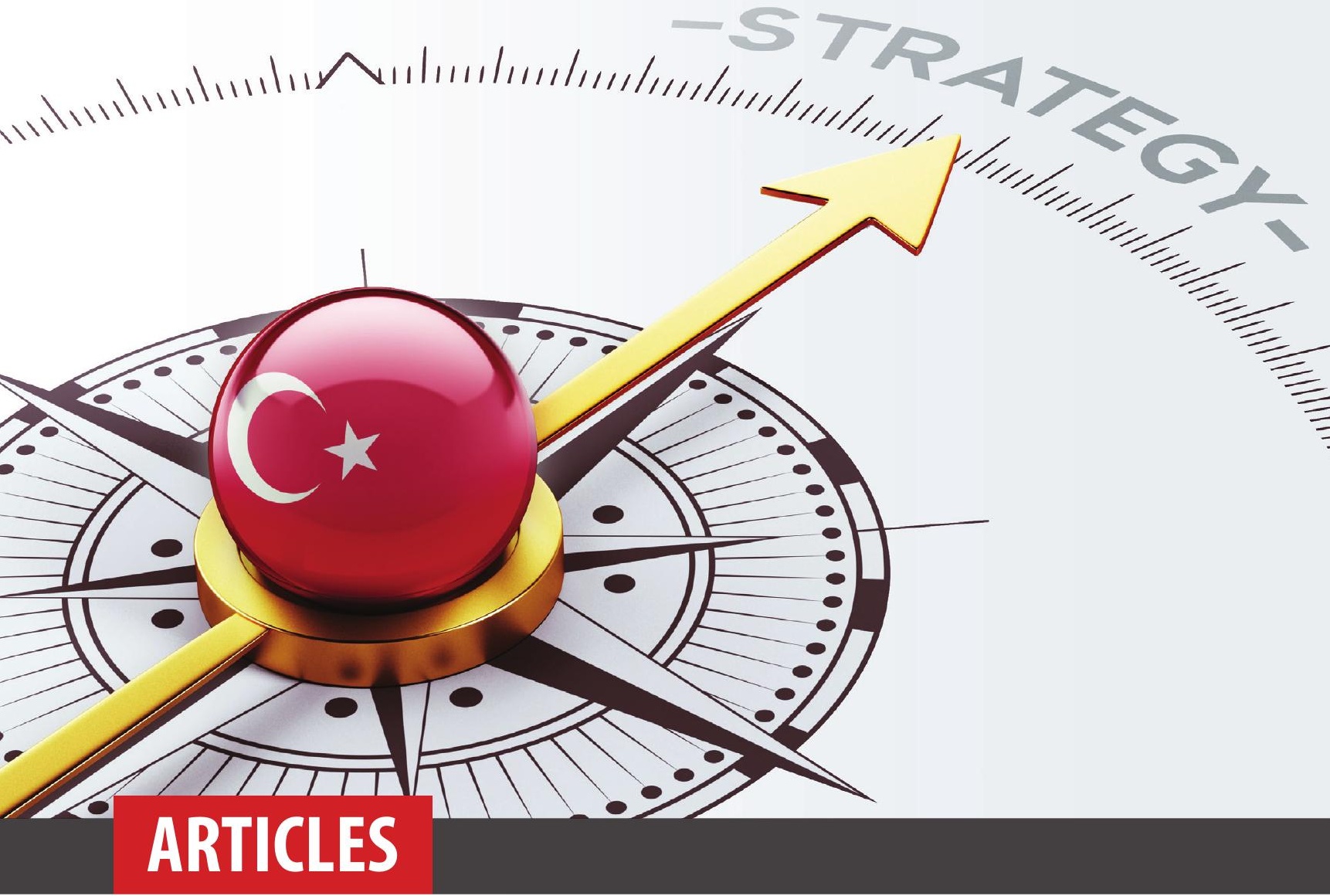

Exploring the Traits of a Grand Strategy for Turkey: Resilience, Protean Power, and Connectography HASAN YÜKSELEN

Turkey's Grand Strategy and the Great Powers ŞENER AKTÜRK

Turkey's Strategic Conduct under the Changing International System MURAT YEŞiLTAŞ and FERHAT PIRIINÇÇi

The Intersection of Grand Strategies in Turkey-Russia Relations: Reflections of Smart Alignment and Flexible Competition in the International Arena ALPEREN KÜRŞAD ZENGIN and ILYAS TOPSAKAL

The Role of Turkish Drones in Azerbaijan's Increasing Military Effectiveness: An Assessment of the Second Nagorno-Karabakh War HÜLYA KINIK and SINEM ÇELIK
The Turkey-UK Free Trade Agreement in Terms of Economic Diplomacy KAAN YIĞENOĞLU

Russia's Policy During the 44-Day Karabakh War NAZIM JAFAROV and ARAZ ASLANLI

Will the Rise of China Transform the International System?

KEMAL INAT and MELIH YILDIZ

The Washington Agreement: A Supplementary Document to the EU Efforts in Kosovo? ANDREJ SEMENOV 


\title{
Exploring the Traits of a Grand Strategy for Turkey: Resilience, Protean Power, and Connectography
}

\author{
HASAN YÜKSELEN \\ Independent Researcher \\ ORCID No: 0000-0002-9852-5168
}

ABSTRACT The international system is experiencing profound changes and has taken on an uncertain character as a result. The concept of strategy and its study has closely followed this trend, and new concepts have emerged both to adapt to and theoretically describe the practical changes and challenges it has engendered. This article explores the ill-suited features of mainstream debates and theorizing from a Turkish perspective and suggests that a critical realist analysis of agential strategizing is most useful to addressing the emerging context. It argues that Turkey has a long pursued grand strategy, but new concepts -resilience, protean power, and connectography - can enhance Turkey's ability to strategize and can enrich the lately emerged vibrant debates exploring Turkey's grand strategy.

Keywords: Grand Strategy, Critical Realism, Protean Power, Resilience, Connectography 


\section{Introduction}

$\mathrm{n}$ recent years, Turkey has faced a series of challenges and threats that have emerged out of shifts in the international system and the resultant growing instabilities and risks that are flourishing in its neighborhood. This new cycle of challenges has compelled Turkey to seek a new outlook on these developments and events, which ought to be comprehensive, novel, and innovative in character. In parallel, debates have emerged that suggest Turkey is pressed to articulate a new grand strategy capable of coping with these challenges and risks, based on a subjective reading from its own uniquely situated perspective. The basic question that the debate revolves around consists of the following questions: Does Turkey need a grand strategy? What should Turkey's grand strategy be? While the former question arose out of skepticism toward the idea of middle powers possessing a grand strategy in the first place, the latter emerged from the perspective of proponents who think that Turkey should (and does) articulate and execute a grand strategy both to resolve the contradictions it faces and to increase its international standing. Irrespective of the question of whether Turkey needs a grand strategy, essentially, the growing debate provides invaluable contributions to the efforts of intellectual explorations on this topic.

This article suggests that Turkey has already long pursued a grand strategy, at least in the sense of a vision and an ultimate goal, from the onset of the Republican period, a grand strategy that aims to ensure and enhance the agency of the country 'to attain the level of civilized nations and outpace that level.' In this context, this article is not designed to address Turkey's need for a grand strategy or to suggest a clear-cut grand strategy that should be executed without any improvisation. Rather, it explores the possible traits and attributes that should be incorporated into a grand strategy for Turkey, given that the international system is undergoing a significant change and that Turkey's region is facing a transformation that is inherently prone to producing a new cycle of challenges and risks.

The first part of the study critically discusses the main features that stand out among the mainstream theorizing on strategy. The second part explores the impulses of change that negate this mainstream theorizing and provides an alternative approach to theorizing founded upon critical realism, which explores how unobservable social structures can implicate agents to recast their strategies. The third part narrows the discussion down into grand strategy for Turkey based on its contextuality and praxeology. The following section is dedicated to exploring the traits of grand strategy, which are identified as resilience, protean power, and connectography; and argues that Turkey can enhance its strategizing in an uncertain environment by incorporating those concepts. This section attempts to provide a snapshot of the practical appli- 
cations of these concepts and how, in some instances, Turkey is already utilizing them.

\section{Identifying the Features of Mainstream Theory on Strategy}

The existing literature has widely focused on the grand strategies of the great powers. Indeed, as Murray argues, "grand strategy is a matter involving grand states and great states alone... no small states... possess the possibility of crafting a grand strategy." This erstwhile normative position essentially states that only the great powers have the capability and capacity to conceive and execute a grand strategy. However, with the transformation of the unipolar international system into a multi-polarity, a growing literature has begun to emerge that argues that middle powers, as well as small states, may also devise a grand strategy, ${ }^{2}$ irrespective of their constraints and the limited resources available to them to allocate in realizing their intended objectives.

To further elucidate the transformation of this outlook, this article will outline the features that stand out in the existing literature and highlight the lacking and misleading aspects of mainstream theorizing in order to facilitate endeavors to explore and ultimately pick the most salient traits that should be incorporated in strategizing.

The mainstream approaches to grand strategy share a number of features. First and foremost is the underlying philosophy of science that leads and frames, if not, narrows and dominates the studies on the concept. Positivist understanding, because of its focus on observables, inevitably reduces the study of the concept to the available means that can be employed to the objectives of the ends. ${ }^{3}$ Beyond reductionism, this approach inherently introduces the reification of ends. This preoccupation with the means that inadvertently reifies and hence, neglects the ends of strategy from a wider perspective, leaves realism as the most viable theoretical approach and introduces neighboring concepts such as geopolitics and power to enhance the viability and credibility of the studies.

As stated above, the conception and study of the material aspect of strategy inevitably brings about the reification of ends in favor of means. In such a situation, when faced with a reductionist approach, what remains at hand to be studied meaningfully, or as claimed by the positivists, scientifically, is the available means at disposal that can be mobilized for the realization of the strategic ends. However, as the world lastly observed in Afghanistan where the Taliban defined its strategy through the adage, 'you have the watches but we have the 


\section{Three essential structures that implicate agency include the international political system, the global economy, and geography}

time,' thus countering the material with the ideational approach, proved the effectiveness of the latter in actualizing strategic ends.

Another contradiction emerges out of this theoretical stance, which can be summarized as the study of grand strategy predicated on realist-oriented assumptions, even though the actors, hereafter the agents, practice their grand strategies within an international order that is characterized by liberalism. In other words, the contradiction emerges out of the power-oriented study of the concept in a choice-oriented international order. Put differently, agents presume that they act ultimately to reach a liberal order with realist means. Irrespective of the continuing and irreconcilable debate, geopolitics still play a determining and predominant role in strategizing.

Although the concept of strategy is a realist-leaning term, geopolitics constitutes the unspoken, driving mindset behind the strategic moves of agents. Geopolitics was blamed for having produced two world wars and, as a remedy, the concept of strategy was introduced to mitigate the negative connotations ascribed to the concept of geopolitics. Therefore, strategy as a concept was devised and began to be studied as a reaction to two world wars. However, mostly due to its positivist orientation, the concept could not make a significant breakthrough with the traditional approaches until recent developments in international relations occurred that compelled practitioners and academics to adopt a revised approach.

The third feature that stands out is the great-power-oriented study of the concept of strategy. This feature can be seen as an outcome of the positivist and means-oriented approach to the study, as the concept carried a sense that only the great powers have the necessary and available means to define and execute a grand strategy. However, the concept was founded upon a post-world wars rationale that left a number of powers capable of exercising such strategy. Put differently, bipolar and unipolar theorization inevitably fell behind in acknowledging and thus addressing the realities of the multipolar world. As Aron points out, "political ends are diverse, but cannot be reduced to the will for power."

\section{Exploring the Changes that Negate the Mainstream Analysis}

While the abovementioned features retained an enduring persistence in the studies, the phenomenon they claimed to address and its study experienced profound changes. One of the most visible changes is the emergence of the 

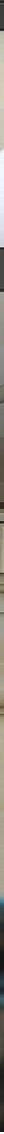

President of

Turkey, Recep

multipolar world. This systemic shift has introduced new dynamics to the study of the concept, which have rendered the traditional ways of study illequipped to acknowledge and correspond to these changes. The situation resembles the analogy of the victor's curse, which suggests that the solutions of the past may be irrelevant or lag behind in terms of what may be necessary to resolve the new challenges as the challenger modifies its understanding. In other words, while new actors introduce novel solutions, the victors presume the old solutions will be as effective as they were in the past. However, outdated solutions cannot resolve contemporary and future problems. This inevitable discrepancy between challenges and solutions is inadvertently prone to producing a different world order that requires novel responses to novel problems.

Tayyip Erdoğan

delivers a speech

at the Victory

Parade held

to celebrate

Azerbaijan's

victory in

Nagorno-

Karabakh, in

Baku, Azerbaijan on December 10 2020.

MUSTAFA MURAT KAYNAK / AA

One of the most significant outcomes of this systemic shift is the proliferation of state and non-state actors, each of whom has its own distinctive ends and means available to resolve the challenges they face. In the international system, the proliferation of actors makes the system more susceptible to producing asymmetric, unprecedented, and diverse challenges that cannot be detected beforehand or tackled well responsively. The proliferation of actors exponentially increases the number of ends, which are extremely difficult to reconcile and commensurate, which indeed is the essential driver of the emerging challenges.

The means allocated to attain the ends have proliferated as well, which has led to the addition of new terms and concepts to the existing lexicon. With the in- 
troduction and experience of the systemic shift, hybrid warfare, proxy warfare, cyber warfare, and lawfare have entered and complicated the debates on strategy. The world has observed how the 'watches and time' metaphor attained success and eventually prompted debates on the degradation of victory into chaos. Indeed, Betz characterizes the outcome in Afghanistan as an example of how 'disconnectedness' triumphed over 'connectedness.'

Consequently, given that profound changes and challenges are being observed and experienced, debates on the attributes of grand strategy should adapt to address the emerging phenomena. At this point, a need has emerged to revamp the concept from an awareness of its shortfalls in addressing the emerging challenges; a theoretical and philosophical approach should be devised to revise the existing understanding with a promising one equipped to address the needs of the new.

\section{Toward an Alternative Theorizing}

Critical realism provides an integrated and dialectical analysis of the interaction of agency and structure. The former refers to actors that are intrinsically motivated primarily to produce a structure on their own terms, while the latter reproduces itself to sustain continuity. Three essential structures that implicate agency include the international political system, the global economy, and geography.

As noted above, the international political system has undergone a substantial change through a proliferation of actors. The global economy, as the basis for means, is being transformed too, through new modes of production conceptualized with terms such as 'Industry 4.0 ' and fintech innovations led by cryptocurrencies. Geography is similarly undergoing reconceptualization on the basis of new connectivities being built and bourgeoning, leading to even more new concepts such as connectography. All of these ground-breaking transformations have substantially changed how the world functions, and inevitably impel agents to adapt to the new realities. Addressing those innovations and path-breaking developments, which are transforming the strategic calculus of agents, necessitates an exploration of the novel attributes of strategy that should be incorporated into strategizing.

Along with their proliferation, non-state actors have also gained some form of agency to alter the actions of state actors, as they either acquired the means to realize their distinct and mostly conflicting ends through cooperation with state actors or were pressed into service to attain the ends of the actors who employ them since they offer themselves as a low-cost means to be employed. In either case, they eventually emerged as agents that should be taken into account in the strategic calculus of states, as they are now irrevocably implicated in the strategic calculus of state actors. ${ }^{6}$ 
It is suggested here that the critical realist approach to strategizing, reinforced with novel concepts, offers what is needed to adapt to the new realities that are emerging but have not yet been addressed adequately. This approach to the concept of strategy situates it within the dialectics of agent and structure. This dialectical approach fosters comprehension of how agents internalize their externalities and externalize their internalities, which will be discussed in greater detail below. ${ }^{8}$ The concept of strategy here is defined in its very simplest terms -the alignment or matching of means and ends- in order to not be encumbered by and to mitigate the preconceived and arbitrary borders and frames imposed by positivist thinking. Unlike positivist approaches, critical realism, by offering greater room for the analysis of agency, allows the inclusion of ends into the analysis. It treats strategy as an agential attribute that consists not only of available means but also of the ends that drive the means. In other words, instead of adopting a binary stance that suggests either means drive ends or ends drives means, the critical realist approach to strategy handles the question of strategizing from a dialectical position that focuses on how means and ends co-constitute and co-evolve in a structured context. ${ }^{9}$

Since the act of strategizing is a "goal-directed activity"10 that is determined to transform a "potentiality into actuality," it is inherently an attribute of the agency. Faruk Yalvaç underlines the agential role in strategy by suggesting that "strategy is what states make of it." 12 In fact, this point relies on the understanding that "if subjectivity is no longer present at the receiving end, then it is also no longer present at the exercising end." ${ }^{13}$ However, this neither neglects the role of means available to be allocated to realize the strategic ends nor reifies the ends as it manifests itself in the strategic mind of the agents. It actually adopts an approach that suggests the two elements of strategy should be considered together and eventually aligned.

The questions then arise, 'how should the agent strategize?' and 'what is the source of agential competencies?' to successfully navigate the uncertainties and challenges being faced. Essentially, this can be seen as an encounter between agents and structure, or internality and externality. The surrounding and conditioning (constraining or enabling) factors constitute the externality of agents, in which the agent, through its agential attributes such as consciousness, cognition, reflexivity, intentionality, etc., ${ }^{14}$ portrays its externality with an internal reading shaped by agential attributes. Once the agent becomes capable of identifying a contradiction, it might prefer to resolve it through 
Grand strategy, in

a similar vein, can

be defined as a

'vision' that leads the

foreign policy of a

country agential action, as the perceived contradiction could involve factors that might be harmful to its overarching objectives. In this dialectical process, agents internalize their externalities and externalize their internalities ${ }^{15}$ precisely by strategizing. Here, there is a dialectical reading and correspondence that interacts, constitutes, and accommodates context and shapes the ongoing agential praxis.

The act of strategizing is essentially an act of positioned practice (praxis) ${ }^{16}$ which "denotes the appropriation and transformation"17 of the constraining circumstances that were imposed by the structure into desired ones that would enable further room for agency. In that process, the knowledgeability of the agents plays an essential role, which will be further discussed as we outline the traits of grand strategy. ${ }^{18}$ However, the structures do not reveal themselves with their implications unless agents become aware of and conceive them (i.e., the implications are concept-dependent), and unless they decide to act (activity-dependent) within the defined contextuality (spacio-temporal-dependent). ${ }^{19}$ In other words, agential awareness conditions agential acts, through which process thoughts are transformed into actions. ${ }^{20}$ In that sense, strategizing occurs within dialectics of 'what is imposed' by the structure and 'what is exposed' by the agents.

\section{Grand Strategy for Turkey: Contextuality and Praxeology}

The reemergence of grand strategy thought and the reinvention of the debate over it, specifically over the propriety of incorporating actors other than great powers, has echoes in Turkey. Apart from being a more inclusive debate, the transformation taking place within the structures has inflicted new uncertainties and challenges that should be tackled with/by agents other than great powers. The transformation is taking place at levels of structures, therefore compelling states other than the great powers to recast the concept of strategy. In parallel, there is growing, vibrant literature in Turkey that explores the question of what Turkey's grand strategy should be..$^{21}$ These trends are a reflection of growing uncertainties and the challenges and contradictions posed by the unprecedented transformations in structures that both enable and constrain agential action. This article aims to contribute to the literature by suggesting that the philosophy of science (positivism) behind the debates is ill-equipped to address the emerging, novel challenges. If the contextuality, as it was discussed above, has changed and continues to change, then the praxeology should also align itself with these changes to accommodate itself to the new.

The literature contains a vast array of definitions of grand strategy, each highlighting different aspects of the phenomenon. To adopt a simplistic definition 
that consists of basic tenets of grand strategy are thought to be more encompassing, similar to defining strategy as the match of means and ends. Grand strategy, in a similar vein, can be defined as a 'vision' that leads the foreign policy of a country. ${ }^{22}$ What is meant by the term 'vision?' A distant future, a place that is aimed at, the goals that are sought to be attained can be cited among the elements of the definition.

In regard to Turkey, one can explore the elements of its vision by uncovering the enduring themes and narratives that might be said to characterize and steer the direction of its domestic and foreign policy to flesh out its grand strategy. From a historical perspective, there is a continuation of one predominant theme and narrative: 'to attain the level of civilized nations and outpace that level.' This theme has provided an overarching grand strategic vision and guidance, which has continuously been adopted by successive Turkish governments irrespective of their political orientation. Different administrations have employed various means, but no major fluctuations have been observed in terms of the ultimate goals or ends. ${ }^{23}$

The existence of a grand strategy vision, as an ultimate goal, does not exhaust the debate and the need for strategy(ies) in support of the grand strategy. From that perspective, a grand strategy can be conceived as a 'strategy of strategies.' The crucial point is that a grand strategy should integrate all complementary strategies under its umbrella, or within its paradigm. They should be interconnected; in this sense, grand strategy can be conceived as a unified system within which each action is committed to reinforcing and complementing every other action, all of which, in the end, converge to attain an overarching purpose and goal, defined as a vision.

In practice, because grand strategy covers a long period, the short-term strategies devised in response to emerging challenges and contradictions might hamper its larger goals. Structures may not always produce such contradictions; in some periods, depending on the evolving context, they may also generate a conducive environment to employ new openings for the realization of the long-term vision. While the former leads to threat-oriented strategies, the latter allows for the formulation of vision-oriented strategies. But both represent some form of continuity irrespective of their conjectural differences. In both cases, whether a particular short-term strategy is a threat- or vision-oriented, maintaining an awareness of the agent in its encounter with the structures is essential to devising a competent long-term strategy.

Context, with its enabling and constraining dynamics, may produce either permissive conditions that produce a vision-oriented strategy, or restrictive circumstances that lead to a threat-oriented strategy. The question then arises, what prompts the nature of the praxis? Praxis is the dialectical out- 


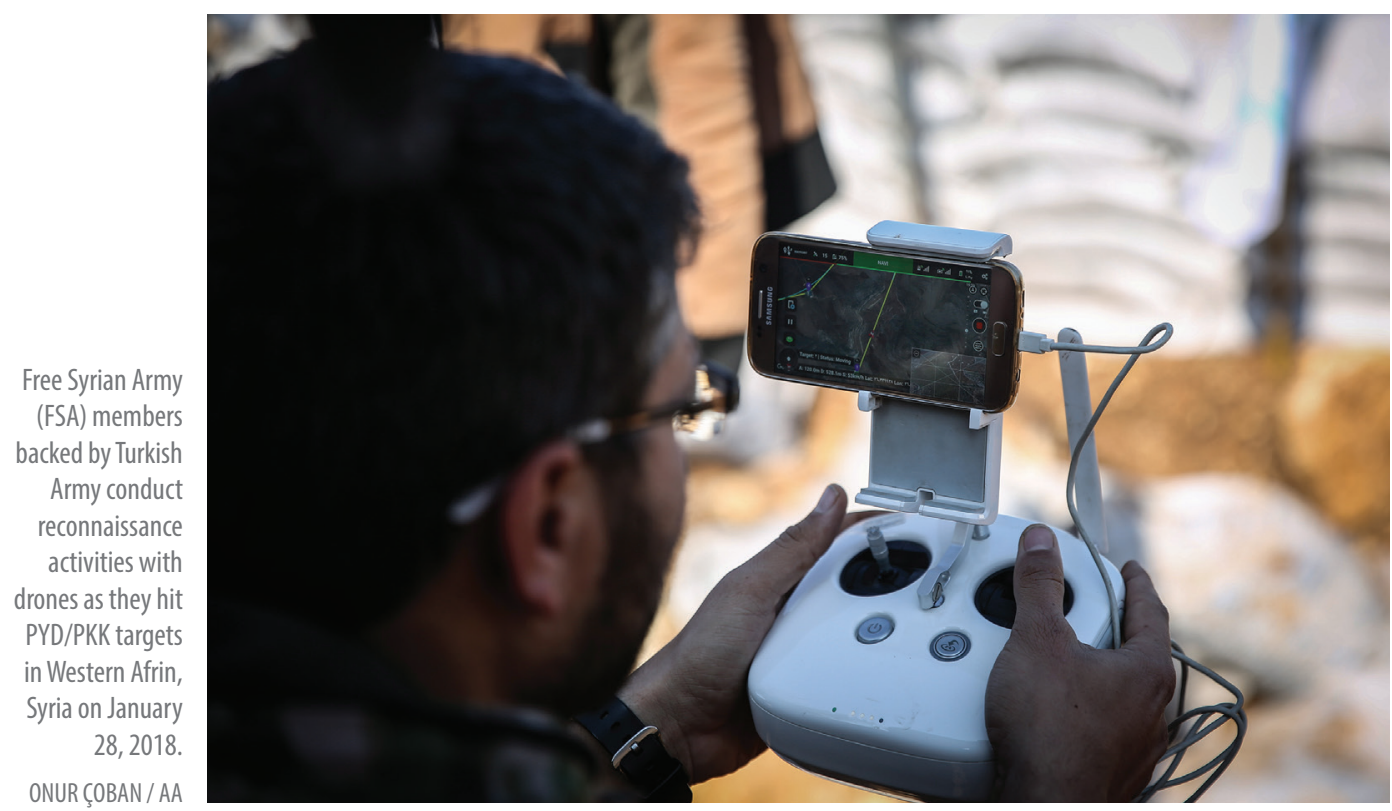

come of the agents' encounter with the context, either experienced or expected. For agents, the major determinant is the conception of the context that it operates within or the expected context. Praxeology is linked with the inception of an idea that underlies the transformation of thinking into action. In other words, while logos provides agential knowledge, praxis employs know-how. But the nature of the strategy, reactionary or precautionary, is conditioned with the agential awareness of an existing and emerging contextual contradiction.

\section{Exploring the Traits}

As noted above, this section is not intended to suggest a grand strategy framework. Instead, focusing on the attributes and traits that correspond to the new realities of the changing world is far more important. Attempting to produce design-type strategies by relying on the chimera of solid frameworks could be misleading and might create short-sighted strategies, whereas attempting to frame dynamic and agile suggestions could result in far-sighted and competent ones. Three novel concepts: 'resilience,' 'protean power', and 'connectography' can enhance the competence of strategizing in emerging contexts that are replete with uncertainties.

\section{Resilience}

Uncertainty necessitates enhanced agential awareness of evolving trends and situations that might either constrain or enable strategizing. When facing unprecedented developments, the agency requires greater awareness and con- 
sciousness in order to detect what is disturbing, challenging, and contradictory, what is eroding, and what is promising. Agential awareness also equips agents with qualities that will enhance their capacity to cope with these developments effectively. The concept of 'resilience ${ }^{24}$ stands out as one of the most important attributes of the agency since it connotes the ability to resist shocks and adjust to emerging uncertainties. Resilient agents retain the ability to strategize in unpredictable times.

Resilience is sensitive to time ${ }^{25}$ since agential acts are spacio-temporal dependent on structures, a contingency that urges agents to constantly monitor developments and improvise their strategizing to adapt to emerging contexts. Agential awareness, which is a function of knowledge production, introduces another concept: contextual intelligence. Joseph Nye defines contextual intelligence as "the ability to understand an evolving environment and capitalize on trends," ${ }^{26}$ which he believes "will become a crucial skill in enabling leaders to convert power resources into successful strategies." ${ }^{\text {27 }}$ Contextual intelligence requires "using the flow of events to implement a strategy." ${ }^{28}$ As Borbeau notes, "knowledge remains contextual;"29 thus contingent, hence 'intelligence power $^{30}$ stands out as one of the facilitators of agency, together with other knowledge-production capabilities of universities and think tanks. Karl W. Deutsch attributes significant importance to systems of knowing (intelligence community), which are treated as the "nerves of government."31 Recently, intelligence in Turkey has undergone a transformation both institutionally and in terms of its governing mindset. ${ }^{32}$ Enhancing intelligence power provides the ability to think ahead and act ahead, thus offering a competitive advantage and positional superiority with regard to emerging contradictions.

Apart from increasing awareness and therefore the ability to differentiate points of contention and points of contestation, each of which requires different levels of adaptation, intelligence power allows agents to re-align their strategies..$^{33}$ Adaptive strategy, or improvisation, requires constant evaluation of the evolving contexts and the alignment of both means and ends in line with emerging challenges. In fact, dynamism, flexibility, and agility to adapt are outcomes of growing awareness and resilience, which urges agents to recast their strategy in keeping with the reframed context.

\section{Protean Power}

The second trait of strategizing should also be equipped with a new understanding of power, as it constitutes the dispositional element of strategy. As the nature of agents evolves, their capability also undergoes a change -one that under- 
Turkey, like many countries, is facing similar forms of post-truth operations in which misinformation and disinformation are being used to alter public opinion regarding Turkey or to attract support within the country mines traditional power resources. Taking into account the emerging international political system, Joseph Nye rightfully points out the processes of power transition among great powers, and power diffusion away from states. ${ }^{34}$ Turkey founded its strategy on soft power means with the onset of the Arab Spring, However, as the developments of the Arab Spring unfolded, particularly with the introduction of realpolitik on the ground, soft power-oriented means of strategy became irrelevant, as hard power strategies dominated the pace and direction of developments. Eventually, Turkey found itself ill-equipped to navigate these changes, leading it to swiftly revise its strategy. Probably the most challenging new feature of the system is uncertainty, which requires a novel approach to the conception of power.

The concept of 'protean power' offers a new outlook on the problem of power. Traditionally, analyzes have focused on the conception of power as a reflection of positivist theorizing that suggests power can be measurable and, whenever applied, the outcome can be predictable. However, given the fact that unobservable structures might cause the emergence of unprecedented events, and since power refers at times to potentiality rather than actuality, a more comprehensive power conception is needed. In that sense, differentiating between 'control power' and 'protean power' broadens the approach to the concept of power. While the former is effective under conditions of risk - which can be calculablethe latter best serves under conditions of uncertainty - which inherently involves incalculable variables. ${ }^{35}$ Protean power reinforces the resilience of an agent and its adaptive capability while offering a menu of novel means to be utilized in actualizing ends and resolving contradictions emerging out of uncertainty.

Nye distinguishes three faces of power, where the third face is focused on the ability to create and shape perceptions, ${ }^{36}$ thus highlighting the influence aspect of power. Amid growing uncertainty, influence has emerged as a form of power that can be exercised through means other than traditional conceptions of power, which "seeks to change the perception of the situation, not the situation itself." ${ }^{37}$ It corresponds with a newly emerging phenomenon described as 'post-truth', which is defined by Oxford Dictionary as relating to or denoting circumstances in which objective facts are less influential in shaping public opinion than appeals to the emotion and personal belief. Post-truth aims to create a false consciousness that leads agents to make false decisions and not to act on agential terms. The imminent and obvious outcome is the degradation of strategic success. 
Turkey, like many countries, is facing similar forms of post-truth operations in which misinformation and disinformation are being used to alter public opinion regarding Turkey or to attract support within the country. In these efforts, the PYD/YPG terrorist organization's affiliation with PKK terrorism is often ignored or refuted, while its employment as a proxy in the fight against ISIS is promoted. Similarly, to lend it a form of legitimacy, a rebranding of the group under the guise of 'Syria Democratic Forces' has been circulated. Several attempts have been made to delegitimize Turkey's operations to fight against ISIS and legitimize the PYD-YPG with narratives that suggest Turkey is targeting Kurds or releasing ISIS terrorists. When such narratives reach the public, the intended outcome -inspiring suspicion toward Turkey-is achieved. Therefore, to avoid being targeted by such information operations, Turkey should promote means of influence to convey the right messages to the target audiences. This capability can be seen as an element of protean power.

\section{Connectography}

With regard to the changing spacio-temporal context, the spacio-temporal conception of strategy has also faced a transformation in which the domains that enable or constrain strategy have proliferated and become densely interconnected. The concept of connectography, ${ }^{38}$ which can be defined as the emerging cartography of connectivity, addresses the high density of interactions that are either observed or unobserved but real. One of the prominent features of connectography is the new meanings and functionalities attached to the already existing geographies. In that sense, the concepts of geography and connectography are not mutually exclusive; on the contrary, they complement and reinforce each other with the new emerging realities. ${ }^{39}$ Geography still retains primacy and determinacy. Nevertheless, connectography has the potential to transform the nature of the geographies, both in the sense of enabling and constraining the activities of agents residing across multiple geographies and possessing or adding new connections. In that way, novel domains, like cyberspace, have already been incorporated into the calculus of strategy.

Parag Khanna's description of Turkey exemplifies the shift and complementarity of the two concepts: "Turkey has been called as the country where the continents collide, now it is the country where the continents connect." 40 The increasing number of connections in all directions seen or unseen have diversified interactions, deepened ties, increased stakes, and multiplied the number of stakeholders who are part of them and hence fostered the enabling factors of strategizing. While Turkey has managed to overcome the confines of the traditional 'bridge or barrier' metaphor, connectivity has increased and is improving the resilience of the country. In fact, unlike the traditional understanding of strategy, this novel approach seeks not to conquer but to connect. ${ }^{41}$ And it has the potential to generate means that can be utilized in the form of protean power. 
Turkey's projects to increase interactions with African countries and initiatives like 'Heart of Asia-Istanbul Process' have added new impetus to Ankara's interactions with those two continents. Being fortunate in terms of not having negative historical baggage and resentments, Turkey's interactions with those geographies are going smoothly and adding new ones to connectivity. In fact, they have welcomed Turkey's interactions, and Ankara's efforts are not being perceived as driven by an irredentist approach. Although disadvantaged by lacking linguistic affinity with post-colonial countries, thanks to not being part of the traumas and exploitation of their colonial past, Turkey has been readily welcomed, since the growing relations are not aimed at exploitation but toward the mutual benefit of the interacting agents. In other words, rather than unilateral imposition, the relationship is built upon bilateral dialogue with the consent of both parties. Those who have found Turkey's overtures threatening are mostly the old colonial powers; French President Emmanuel Macron has attempted to situate Turkey in colonialist terms with a reference to the Ottoman past in Africa. Thanks to growing agential awareness in those countries, however, Macron's messages have not been received positively.

Diversified and dense connections and interactions can reinforce the attribute of resilience. During the Operation Peace Spring Turkey experienced tensions with the U.S. which symbolized with President Trump's threatening language -'obliterate' - that targeted Turkish economy. It is possible to become more resilient to sanctions, which are utilized to create economic pains for political gains, through connectography. Circumventing sanctions such as Countering America's Adversaries Through Sanctions Act (CAATSA) can be cited among the contributions of a changing understanding of spacio-temporal context, conceived as connectography-based resilience. In fact, connectography reinforces complex interdependence with a novel understanding and is essentially a liberal approach. While connectivity has the potential to reduce proclivity to war, it might also spark resentment among other agents, as it infiltrates into geographies with positive agendas, which were thought to be the backyard of former colonial powers, as was lately observed in Africa and with France.

Connectography, although conceived with a liberal understanding, entails realist elements in itself, at least in the sense that fostering liberal interactions might be ensured through hard power assets such as drones. Turkey has applied this strategy in different geographies with an asymmetric understanding that curtailed the impacts of proxy warfare with drone warfare. In Syria, Libya, and Karabakh the applied strategy was defensive in character, while a vision ingrained into the use of military options.

In Syria, Turkey faced unprecedented and enormous threats posed by the PYD/ YPG, which aimed to create an autonomous region bordering Turkey, thus capturing an opportunity to spread its terror threat into Turkey and threaten the 
unity of Syria through demographic engineering. Consequently, Turkey initiated a series of operations to eliminate the terror threat that had emerged from Syria. Most significantly, Turkey faced 'proxy' warfare waged against itself. Obama's hesitance to arm the moderate opposition in the early days of the Syrian Uprising with the fear that 'the delivered weapons might end up in wrong hands' evolved into the armament of a terrorist organization, which was 'leweapons not only to end up in the wrong hands but to be directed against a traditional NATO ally. Turkey, upon assessing the deteriorating security situation, responded with drones to eliminate and constrain the impacts of this proxy warfare. ${ }^{42}$ In fact, the operations in Syria were threat-oriented strategic acts in essence that enabled a vision-oriented outlook to the region.

In Libya, upon warlord Haftar's assault on Tripoli and the ensuing request from the UN-recognized Government of National Accord (GNA) for assistance from the international community to repel the assault, Turkey agreed to provide military training and assistance. Subsequently, a ceasefire was enacted with the objective of conducting free and fair elections to unite the country and eliminate the impacts of the use of force by warlords. In the Libyan case, Turkey preserved the legitimacy of the international community and the UN by not allowing the ousting of a legitimate government by a warlord and consequentially facilitating the ground for elections. For Turkey, this intervention also assisted the process of laying the groundwork to establish connectivity with the African continent. In other words, through Libya, Turkey succeeded in transforming the poor demarcation of the colonial era into connectivity, through which the turmoil, traumas, and inherited under-development and exploitation of the past can be healed through the positive atmosphere of connectography. ${ }^{43}$

The recent Karabakh conflict was an operation to liberate the territories of Azerbaijan that had been illegally occupied by Armenia for almost three decades, despite the fact that several UN Security Council Resolutions and peace processes had been attempted under the auspices of the UN, e.g., the Minsk Group, to resolve the dispute. Operations to unite the Azerbaijan territories facilitated the elimination of the artificial divisions created by the frozen conflicts. In fact, Armenia itself had become a captive of the old stereotypes; as Parag Khanna underlines, the "landlocked countries are prisoners of geography, and connectivity is the only way out." ${ }^{\prime 4}$ The Karabakh conflict eliminated a burden from Armenia, and if Yerevan consents, new historiography based 
upon connectography can be written that can potentially replace outdated enmity with visionary amity in the region.

\section{Conclusion}

While the international system is experiencing significant transformations, the traditional theorizing on strategy is caught ill-equipped. This situation calls for the utilization of new concepts that are more comprehensive in addressing the pressing changes. Traditionally, grand strategy debates were more realist-leaning and great power-oriented and primarily tended to focus on means at the expense of ends. This inclination is an inherent outcome of positivism, which focuses on observables. Applying critical realism as a philosophy of science and a way to acquire knowledge of reality beyond observables yields a theorizing strategy with a more comprehensive perspective. Critical realist analysis, which locates the act

\section{Turkey already has a grand} strategy, at least in terms of a vision, and this grand strategy, without a connotation of an 'other,' identifies a dynamic strategic end for the country of strategizing within the dialectics of agent and structure, broadens the debate to include the unobservable and mitigates the gaps inherent in the positivist analysis of strategizing.

The term 'grand strategy' is more encompassing compared to the term 'strategy', as it refers to longer-terms and higher ends. As both concepts face similar challenges in effectively addressing the uncertainty and dynamism produced by the evolving international system, capitalizing on new concepts that are more apt to articulate and address the novel challenges have become inevitable. Even though substantial continuities persist, explorations of novel concepts broaden perspectives and triggers debates on the topic. With the objective of contributing to the preexisting, vibrant debate on grand strategy, this article has explored several theoretical and conceptual gaps and the possible remedies that have the potential to address them.

In the contemporary international system, the proliferation of agents, the transformation of structures, the erosion of power bases through the transition of power among great powers, and the diffusion of power away from states necessitates the utilization of dynamic concepts such as connectography, protean power, and resilience to complement existing theorizing and strategizing. These concepts are not chosen because they are exhaustive, but to broaden, and introduce dynamism to the debate.

As suggested from the very beginning, Turkey already has a grand strategy, at least in terms of a vision, and this grand strategy, without a connotation of an 
'other', identifies a dynamic strategic end for the country. Since the Republican period, this strategy has continued to be pursued irrespective of successive governments' political orientations. Apart from the negligible differences emanating from the character and realities of the evolving context, this strategy-maintained continuity. Fluctuations in continuity emerged out of various agents improvisation to respond to the changing context, which led to the implementation of either threat-oriented or vision-oriented strategies within the larger, unifying vision.

Within the newly emerging present-day context, Turkey has already started to employ the novel concepts discussed here. Conceptualizing them in order to further incorporate them into Turkey's strategizing has the potential to increase the effectiveness of its strategies in today's continuously unfolding, uncertain environments.

\section{Endnotes}

1. Williamson Murray, "Thoughts on Grand Strategy," in Williamson Murray, Richard Hart, and James Lacey (eds.), The Shaping of Grand Strategy: Policy, Diplomacy, and War, (New York: Cambridge University Press, 2011), pp. 1-2.

2. Thierry Balzacq, Peter Dombrovski, and Simon Reich, Comparative Grand Strategy: A Framework and Cases, (Oxford: Oxford University Press, 2019).

3. Richard Wyn Jones, Security, Strategy and Critical Theory, (Boulder, CO: Lynne Rienner, 1999), p. 129.

4. Muriell Cozette, "Realistic Realism? American Political Realism, Clausewitz and Raymond Aron on the Problem of Means and Ends in International Politics," Journal of Strategic Studies, Vol. 27, No. 3 (September 2010), p. 440.

5. David Betz, Carnage and Connectivity: Landmarks in the Decline of Conventional Military Power, (London: Hurst, 2015), p. 35.

6. Hasan Yükselen, Turkey and Russia in Syria: Testing the Extremes, (Ankara: SETA, 2020).

7. Alexander Wendt, "The Agent-Structure Problem in International Relations," International Organization, Vol. 41, No. 3 (1987), pp. 335-370; Colin Wight, Agents, Structures, and International Relations: Politics as Ontology, (Cambridge: Cambridge University Press, 2006); David Dessler, "What's at Stake in the Agent-Structure Problem," International Organization, Vol. 43, No. 3 (1989), pp. 441-473; Audie Klotz, "Moving Beyond the Agent-Structure Debate," International Studies Review, Vol. 8, No. 2 (2006), pp. 355-381.

8. Pierre Bourdieu, Outline of a Theory of Practice, (Cambridge: Cambridge University Press, 1977), p. 205.

9. Hasan Yükselen, "Strateji Kavramını Çalışmak [Studying the Concept of Strategy]," Journal of Security Strategies, Vol. 14, No. 27 (2018), pp. 1-38.

10. Richard J. Bernstein, Praxis and Action: Contemporary Philosophies of Human Activity, (Philadelphia: University of Pennsylvania Press, 1971), p. 43.

11. Christian Heine and Benno Teschke, "Sleeping Beauty and the Dialectical Awakening: On the Potential of Dialectic for International Relations," Millennium, Vol. 25, No. 2 (1996), p. 414.

12. Faruk Yalvaç, "Strategic Depth or Hegemonic Depth? A Critical Realist Analysis of Turkey's Position in the World System," International Relations, Vol. 26, No. 2 (2012), pp.165-180.

13. Jonathan Joseph, "Foucault and Reality," Capital and Class, Vol. 28, No. 1 (2004), p. 152.

14. Jonathan Joseph, "Hegemony and the Agent Structure Problem in International Relations: A Scientific Realist Contribution," Review of International Studies, Vol. 34, No.1 (2008), p. 117. 
15. Bourdieu, Outline of a Theory of Practice, p. 205.

16. Frederic Merand and Amelie Forget, "Strategy: Strategizing about Strategy," in Rebecca Adler-Nissen (ed.), Bourdieu in International Relations: Rethinking Key Concepts in IR, (New York: Routledge, 2013), pp. 93-113, p. 104.

17. Heine and Teschke, "Sleeping Beauty and the Dialectical Awakening," p. 413.

18. John Scott, "Where Is Social Structure?" in José Lopez and Garry Potter (eds.), After Postmodernism: An Introduction to Critical Realism, (London: The Athlone Press, 2001), p. 84.

19. David Harvey, "Agency and Community: A Critical Realist Paradigm," Journal for the Theory of Social Science, Vol. 32, No. 2 (2002), p. 170; Roy Bhaskar, The Possibility of Naturalism: A Philosophical Critique of Contemporary Human Sciences, (New York: Harvester Wheatsheaf, 1989), p. 38; Benno Teschke and Can Cemgil, "The Dialectic of the Concrete: Reconsidering Dialectic for IR and Foreign Policy Analysis," Globalizations, Vol. 11, No. 5 (2014), p. 619.

20. Teschke and Cemgil, “The Dialectic of the Concrete," p. 616.

21. Murat Yeşiltaş and Ferhat Pirinççi, Türkiye'nin Büyük Stratejisi, (İstanbul: SETA, 2020); Perceptions: Journal of International Affairs, Vol. 25, No. 2, (Winter, 2020); Ali Karaosmanoğlu and Ersel Aydınlı, Strateji Düşüncesi: Kuram, Paradoks, Uygulama, (İstanbul: Bilgi Üniversitesi Yayınları, 2020).

22. Braz Baracuhy, "The Art of Grand Strategy," Survival, Vol. 53, No. 1 (2011), p. 147.

23. Hasan Yükselen, Strategy and Strategic Discourse in Turkish Foreign Policy, (Basingstoke UK: Palgrave Macmillan, 2020).

24. Philippe Bourbeau, On Resilience: Genealogy, Logics, and World Politics, (Cambridge: Cambridge University Press, 2018).

25. Bourbeau, On Resilience, p. 15.

26. Joseph S. Nye, The Powers to Lead, (Oxford: Oxford University Press, 2008), pp. 85-108.

27. Joseph S. Nye, The Future of Power, (New York: Public Affairs, 2011), p. xvii.

28. Nye, The Powers to Lead, p. 88.

29. Bourbeau, On Resilience, p. 29.

30. Michael Herman, Intelligence Power in Peace and War, (Cambridge: Cambridge University Press, 1996).

31. Karl W. Deutsch, The Nerves of Government (New York: Free Press, 1963).

32. Merve Seren, "Türk İstihbaratının Değişen Dinamikleri: Son 10 Yılda Reform Siyasal ve Operasyonel Açılım," Tesam Akademi Dergisi, Vol. 8, No. 2 (2021), pp. 371-405.

33. Bourbeau, On Resilience, p. 28.

34. Nye, The Future of Power, pp. vii-viii.

35. Peter J. Katzenstein and Julia A. Serbert, Protean Power: Exploring the Uncertain and Unexpected in World Politics, (Cambridge: Cambridge University Press, 2018).

36. Steven Lukes, Power: A Radical View, (New York: Palgrave, 2006).

37. Moisés Naim, The End of Power, (New York: Basic Books, 2013), p. 27.

38. Parag Khanna, Connectography: Mapping the Future of Global Civilization, (New York: Random House, 2016).

39. Khanna, Connectography, p. 16.

40. Khanna, Connectography, p. 7.

41. Khanna, Connectography, p. 28.

42. Yükselen, Turkey and Russia in Syria.

43. Khanna, Connectography, p. 93.

44. Khanna, Connectography, p. 203. 